\title{
The Measurement of Competitiveness of Hong Kong International Shipping Center and Its Promotion Strategies
}

\author{
Dongxiang Fan \\ Hong Kong and Macao Economic Research Institute, College of Economics, Jinan University, Guangzhou, China \\ Email:641428919@qq.com
}

How to cite this paper: Fan, D.X. (2019) The Measurement of Competitiveness of Hong Kong International Shipping Center and Its Promotion Strategies. Modern Economy, 10, 853-871.

https://doi.org/10.4236/me.2019.103057

Received: February 18, 2019

Accepted: March 19, 2019

Published: March 22, 2019

Copyright (อ 2019 by author(s) and Scientific Research Publishing Inc. This work is licensed under the Creative Commons Attribution International License (CC BY 4.0).

http://creativecommons.org/licenses/by/4.0/

\begin{abstract}
In recent years, the competition among international shipping centers has become more and more fierce. The development of Hong Kong international shipping center is not optimistic. Based on this, we analyzed the factors affecting the competitiveness of international shipping centers and constructed the competitiveness evaluation index system of international shipping center. We used the Entropy Weight and TOPSIS method to conduct empirical research on the competitiveness of four shipping centers in Hong Kong, Shanghai, Singapore, and Shenzhen to clarify the current location of the Hong Kong international shipping center and the differences with other shipping centers. According to empirical findings, we have proposed some strategies to enhance the competitiveness of Hong Kong international shipping center from the perspective of competition and cooperation.
\end{abstract}

\section{Keywords}

Hong Kong, International Shipping Center Competitiveness, Cooperation and Competition, Promotion Strategies

\section{Introduction}

For a long time, Hong Kong has always been one of the most important international shipping centers in the Asia-Pacific region because of its unique location in the heart of Asia and its unique location on the mainland, with its natural deep-water port and its "free port policy". As a global financial center and trade center, Hong Kong has a good business environment and a sound judicial system, which has played a positive role in maintaining the competitiveness of its shipping center. However, compared with the development momentum of other 
international shipping centers in recent years, the performance of the Hong Kong International Shipping Center has not been satisfactory. In terms of container throughput, until 2004, Hong Kong ranked first in the global container port rankings. The world's largest container port, and the container throughput of Hong Kong ports has been surpassed by Singapore since 2005, and since then its growth rate has begun to slow down, and its ranking has been declining, gradually lower than Shanghai, Shenzhen and Ningbo Zhoushan. Although the container port ranking does not represent the performance of the overall shipping center, it is a very important aspect. According to the Xinhua-Baltic International Shipping Center Development Index Report (2016), the top three international shipping centers in 2016 were Singapore, London, Hong Kong, and Shanghai ranked sixth. Moreover, Hong Kong has always pursued the "freedom of non-intervention" policy, which is particularly evident for the shipping industry. Although the former Chief Executive of Hong Kong, Leung Chun-ying, proposed in the 2013 Policy Address to support the Hong Kong shipping industry to expand and expand, and to build a high value-added shipping service industry based on the existing terminal business. But in fact, in the past 10 to 15 years, the Government has not given direct policy support or funding to the shipping industry. This shows that the Hong Kong Government has not paid enough attention and support to the shipping industry. The shipping industry is also an important part of the economic basic industry. In 2014, the direct economic contribution of the shipping and port industry to Hong Kong's GDP has reached 30 billion Hong Kong dollars and provided nearly 100,000 jobs. It has a huge role, and the relationship between the shipping center and the financial center and the trade center is inseparable. In particular, the development of the shipping center and the trade center has a particularly strong interdependence and mutual promotion relationship. Therefore, the improvement of the shipping center is important. To enhance the competitiveness of its shipping centres is one of the aspects that can maintain Hong Kong's economic prosperity and stability and the construction of the three centers. And the global port shipping business center has already moved to Asia, especially China [1]. Together with the increasingly close maritime transportation of countries along the Belt and Road, the maritime transportation in the Asia-Pacific region will further promote the development and expansion of the shipping industry in the Asia-Pacific region. The Asia-Pacific region also urgently needs a city like London. A globally recognized international shipping center that provides an authoritative one-stop service for the shipping industry in the Asia-Pacific region. However, in the Asia-Pacific region, Singapore, Hong Kong, Shanghai and other shipping centers are highly competitive. Although there is a gap in strength, there is no distant leader can take this responsibility.

So far, the research on the development of Hong Kong shipping centers has basically remained on qualitative analysis, and there is little empirical research. For example, Wang Yanbin (2014) analyzed the status quo and characteristics of the shipping industry in Hong Kong and proposed targeted measures [2]. Qu 
Jian (2007) combined the status quo to analyze the possibility and necessity of Hong Kong and Shenzhen to build an international shipping center [3]. Zeng Jiawen (2013) from the vertical to the Hong Kong shipping center, the empirical analysis of the influencing factors of competitiveness has neglected the horizontal comparison of different shipping centers, which is not conducive to Hong Kong to determine its development direction by finding its own unique advantages, strengths and weaknesses [4]. At the same time, the research methods on the competitiveness of international shipping centers, most of the existing researches are obtained through the fuzzy comprehensive evaluation method to obtain the final port or shipping center ranking. Some scholars also use the principal component analysis and cluster analysis to classify the ports, and compete for the competition. Most of the weighting of the evaluation index system is based on the expert survey method or subjective analysis by the author himself, and less is handled by objective mathematical methods. Moreover, in the empirical research, it is usually only a one-year cross-sectional data.

Therefore, in the face of the positive development of Singapore, the rise of Shanghai and Shenzhen shipping centers, and the opportunities and challenges brought about by the changes in the environment, it is necessary to focus on the international shipping center in Hong Kong from the perspective of horizontal comparison, and look forward to its new In the context of the era, the search and use of unique advantages different from other international shipping centers to enhance the competitiveness of its shipping center. And this paper analyzes the influencing factors of international shipping center by referring to Porter's "diamond model", and combines the data availability and scientificity to construct the evaluation index system of shipping center competitiveness, so as to meet the true meaning and influencing factors of the competition of international shipping center as much as possible. Then, using the entropy weight Topsis research method to compare the highly competitive shipping centers in Hong Kong, Shanghai, Singapore and Shenzhen, and use objective mathematical methods to deal with the data to avoid the subjective influence of the researchers. At the same time, this paper also adds dynamic data at different points in time to analyze the overall changes of the Hong Kong International Shipping Center, in order to understand the current location of the Hong Kong shipping center and the differences with other international shipping centers, and propose a targeted strategy to Help enhance the competitiveness of its international shipping center.

\section{The Influencing Factors of the Competitiveness of International Shipping Centers and the Construction of Its Evaluation Index System}

With the development of various shipping centers and their increasingly fierce competition, the academic research on the competitiveness of various shipping centers is also increasingly enriched. The research on international shipping centers mainly focuses on concept definition and factor research, formation process and evaluation research. So far, the definition of the concept of an in- 
ternational shipping center is still not uniform. This aspect is because the historical, social, geographical and economic backgrounds formed by international shipping centers vary from place to place, and the concept of international shipping centers is different in different locations. On the other hand, the international shipping center itself is a concept of dynamic development. The time changes and the content is constantly enriched and perfected. In China, there are roughly the following views, Xu Xing (2003) and others believe that "the international shipping center refers to a port city integrating the functions of deep water channel, collecting and distributing network, etc. [5]"; Wu Xiaohui (2004) and others believe that "the international shipping center refers to the port group. The core position of the shipping hub [6]"; Yang Jianyong (2005) and so on that "the international shipping center should be a port-based concept of location function [7]". Although the views are different, they all agree that the international shipping center is based on the port. At the same time, it can be seen from the international shipping center that the business scope of the international shipping center should be international, and the business content should be about the shipping industry, and the degree of business concentration should be high [8]. Therefore, the concept of an international shipping center can be described as: in its core shipping business, there are two or more service areas that are simultaneously globally competitive, and have already scaled cities in terms of supporting functions. The two concepts of international shipping center and hub port are closely related, but there are also differences. The international shipping center has richer and more abstract content. The hub port is more focused on the port and is more targeted. Therefore, the evaluation index system should be different. The former should be more comprehensive and rich, while the latter should be more industry-specific.

1) Factors affecting the competitiveness of international shipping centers

According to the existing literature, there are different opinions on the influencing factors of the competitiveness of international shipping centers. Li Junjun (2003) believes that as an international shipping center, it should have the status of "the hub of marine transportation, integrating commodity flow, information flow, capital flow and talent flow. It also has the ability to serve the global integrated logistics function, which can attract and radiate the flow of goods in the surrounding area and the hinterland [9]" Ma Shuo (2007) believes that the influencing factors of international shipping centers are more reflected in the soft power of shipping services, information, research and development, education and other related industries [10]. Zhang Li (2008) also believes that shipping finance, shipping information, and shipping knowledge are key factors in the shipping center [11]. Wang Xiaohui (2006) believes that the formation of international shipping centers and the factors influencing the maintenance of their competitiveness mainly include: hard environmental factors involving location conditions, collection and distribution networks, and economic hinterland, involving the quality of service and coordinated development of port groups and sustainable development. Soft environment factors, other external 
factors [12]. Throughout the existing literature, the analysis of the formation of international shipping centers and their influencing factors are actually very similar. Most of them are analyzed from the two aspects of hard environment and soft environment. The hard environment mainly involves location conditions, hinterland conditions, port conditions, and collection. In terms of transportation network and other aspects, the soft environment mainly involves the support conditions for the development of shipping services such as finance, trade, information, human resources, and legal policies. The difference is that the research focus of these researchers is different.

According to Porter's "diamond model", factors affecting international competitive advantage include six aspects: production factors, demand status, related and supporting industries, corporate strategy and structure and horizontal competition, government, and opportunities. Based on the above description of the similarities in the existing literature, it is found that the listed influencing factors are basically consistent with Porter's "diamond model". For example, production factors mainly include human resources, natural resources, knowledge and capital resources, and infrastructure. Therefore, port location conditions, hinterland conditions, port conditions, and collection and distribution networks can be classified as production factors; demand status mainly refers to market demand. The foreign trade environment can reflect market demand; the financial, information, and legal environment reflect relevant and supporting industrial factors. Therefore, combined with the actual situation and the connotation of the international shipping center and the above, the factors affecting the competitiveness of the international shipping center can be divided into the following parts: shipping production factor conditions, shipping market demand conditions, shipping related and supporting industrial factors, Auxiliary factor.

a) Conditions of shipping production factors: The conditions of shipping production factors are the most basic conditions for the formation and development of international shipping centers, including the port's natural geographical conditions, port infrastructure construction, the economic development of the port city, the port collection and distribution system, and the human resources environment. .

i) Natural geographical conditions of the port. Good physical and geographical conditions not only make the international shipping center have a higher starting point for development and development, but also make it more potential for development. Different natural geographical conditions will also form different types of ports, such as hinterland type and medium transition. The physical and geographical conditions of the port mainly include the weather conditions of the port, the distance between the port and the international main route, the water depth and width of the channel, the port hydrology, the water depth at the front of the terminal, and the incidence of natural disasters.

ii) Level of port infrastructure. The main function of the port is cargo transportation. The construction and improvement of the port infrastructure is conducive to improving the capacity and efficiency of shipping cargo transportation. The 
port is the foundation of the international shipping center. Therefore, the construction and improvement of port infrastructure is an important factor in the improvement of the competitiveness of international shipping centers. The port infrastructure level is mainly reflected in the length of the dock shoreline, the number of berths, the yard and storage capacity, and the terminal equipment technology.

iii) Economic development of the city where the port is located. The vast economic hinterland provides an important impetus for the formation of international shipping centers and the economic hinterland of maintaining a competitive port. The economic hinterland can be divided into direct hinterland and indirect hinterland, the city where the port is located is its direct hinterland, and the rest is its indirect hinterland. This paper analyzes from the perspective of the city directly in the hinterland, that is, the city where the port is located. The higher the economic development level of the city where the port is located, the greater the promotion of the construction of the shipping center by commodities, capital and information, and the stronger the support for the international shipping center. The economic development of the city where the port is located is mainly reflected in the level of national economic development and its growth rate and industrial structure.

iv) Port collection and distribution system. The degree of perfection of the collection and distribution system of the port determines the efficiency and convenience of the shipment of goods to the port. The more complete the collection and distribution system, the shorter the time it takes for the goods to arrive at the port from the starting point, and the lower the cost, so the customer is more willing to conduct business operations through the port. The collection and distribution system mainly includes land transportation network, air transportation network, internal branch transportation network, and multimodal transportation.

v) Human resources environment. The human resources environment is very important for the construction of international shipping centers. Talents are the most valuable resource of all resources. Because talents have high levels of initiative, they are the basis and premise of all production activities, and the contribution of high-quality talents to economic growth is even more. It will increase in multiples. Various professional talents have also played a supporting role in the construction and competitiveness of international shipping centers. The human resources environment mainly includes the status of managers and professional technicians, the status of highly educated personnel, the income per capita of society, and the speed of knowledge update.

b) Shipping market demand conditions: The shipping market demand conditions are the driving force for the development of international shipping centers. The shipping market demand includes the demand for cargo transportation and deployment and the demand for various shipping related services, such as financing, insurance, education, and law and many more. Among them, the transportation and deployment of goods is the most direct demand, and this demand has spawned other related needs. The shipping industry has a high de- 
gree of industrial agglomeration, so the demand in the shipping market is strong, which will promote the development of the shipping industry and other shipping-related industries. Demand conditions in the shipping market can be mainly reflected in the level of foreign trade and port demand. The level of foreign trade reflects its international trade demand. Port demand directly reflects the port size and demand through container throughput, cargo throughput and transit volume.

c) Shipping related and supporting industry factors: Whether to have internationally competitive related and supporting industries is an important factor in the acquisition and promotion of international shipping center competitiveness. Usually, the formation and development of international shipping centers cannot be separated from financial centers and trade. Support from the center and information center. As an industry with a high degree of industrial agglomeration, the shipping industry will form an associated industrial cluster with other related and supporting industries in the development process. Only the coordinated development and mutual promotion of the entire associated industrial cluster will further enhance the competitiveness of the international shipping center. Moreover, the shipping industry is a capital-intensive global industry. The flow of funds and information is frequent. Therefore, it is closely related to finance and information industry. Of course, it cannot be separated from the support of the law.

i) Financial service environment. The shipping industry is a capital-intensive industry, and a sound financial service environment will provide a strong guarantee for the development of the shipping industry. The developed financial market makes the financing of the shipping industry very convenient, provides financial support for the development of the shipping industry, and the shipping industry is highly risky. Therefore, the demand for insurance is indispensable, and the perfect insurance market is more conducive to the development of the shipping industry. Of course, a good financial services environment will bring many other benefits to the shipping industry, such as currency settlement and liquidation. The financial service environment can mainly be reflected in the value added of the financial industry, the development of the insurance industry, and the financing environment. In fact, the amount of ship financing and ship insurance and ship brokerage institutions can more directly reflect the support of the financial environment to the shipping center.

ii) Information service environment. With the economic development and information technology revolution, information has become a key factor in the success or failure of all walks of life, and the shipping industry is inevitably affected by the information environment. A good information service environment enables people to get the latest developments in the shipping industry in a timely manner, reduce decision-making risks and costs, and improve operational efficiency and service quality. The information service environment is mainly reflected in the network popularization status, the added value of the information industry, the development status of shipping media, the status of shipping 
information consultation and research institutions.

iii) Legal service environment. A sound legal system ensures that all kinds of interest disputes can be dealt with fairly and quickly, so a sound legal system ensures fair competition in the shipping market. Due to the global characteristics of the shipping industry, those who seek legal requirements do not necessarily come from the same place, and do not necessarily apply for arbitration at their place. Generally, the disputes related to shipping are settled by customary methods, so not only must A sound legal system is also a legal system that most people can accept when applying for legal arbitration. Therefore, the legal service environment is mainly reflected in the perfection of the legal system and the degree of international integration.

d) Auxiliary factors: The auxiliary factors mainly refer to the government and opportunities, the opportunities are beyond control, and the influence of government actions cannot be ignored. The government can influence all aspects of the construction of international shipping centers through direct and indirect behavior. For example, the free port policy, the preferential tax policy, the convenient ship registration policy, etc., and the government can also influence the development of the shipping industry through its related and supporting industry behaviors. The improvement of government service quality is also conducive to the construction of international shipping. Opportunities are mainly influenced by external factors, such as competition from other international shipping centers, because competition will also have incentive effects, and changes in some major environments, such as the economic center eastward, will also be accompanied by opportunities.

2) Construction of the competitiveness evaluation index system of international shipping center

According to the analysis of the influencing factors of the above-mentioned international shipping center competitiveness, as well as the scientific, comprehensive, operability and comparability, the international shipping center competitiveness evaluation index system is constructed. The whole indicator system is divided into three levels, namely the target layer, the criteria layer and the indicator layer. The target layer is the competitiveness of the international shipping center. The criteria layer is the conditions of shipping production factors, shipping market demand conditions, shipping related and supporting industrial factors. Auxiliary factors, the index layer includes twenty-five indicators such as the water depth at the front of the dock, the number of container berths, and the GDP of the city where the port is located. The overall legal environment and the degree of special tariff easing on behalf of the government and the overall tax environment indicators are assigned through qualitative analysis. The standard of valuation of the legal environment is the degree of integration of the law and the international law, because the shipping industry is a global industry, and the legal service is not only for local customers. The standard of special tariff easing is whether the place is a free port or whether it has a free trade zone. Since the free trade volume is smaller than the free port, the free port is slightly higher 
than the free trade zone. The overall tax environment is valued according to the tax rate of various taxes, and the low tax rate is high, and vice versa. The specific evaluation index system can be seen in Table 1 .

\section{Methods and Data}

\section{1) Research methods}

This paper uses the entropy weight Topsis method. The method combines the entropy weight method with the Topsis method, which is a sorting method that approximates the ideal solution. Firstly, the entropy weight method is used to determine the weight, and then the weight is used to calculate the relative

Table 1. International shipping center competitiveness evaluation index system.

\begin{tabular}{|c|c|c|}
\hline Target layer & Criteria layer & Indicator layer \\
\hline \multirow{26}{*}{$\begin{array}{l}\text { The } \\
\text { competitiveness } \\
\text { of international } \\
\text { shipping center }\end{array}$} & \multirow{12}{*}{$\begin{array}{l}\text { Conditions of } \\
\text { Shipping } \\
\text { production } \\
\text { factors }\end{array}$} & the water depth at the front of the terminal \\
\hline & & Container berth \\
\hline & & GDP of the city where the port is located \\
\hline & & GDP growth rate \\
\hline & & Per capita GDP \\
\hline & & The proportion of the tertiary industry to GDP \\
\hline & & Tertiary industry output value \\
\hline & & Highway density \\
\hline & & Number of college students per 10,000 people \\
\hline & & Per capita income \\
\hline & & Foreign trade import and export volume \\
\hline & & Year-on-year growth rate of foreign trade volume \\
\hline & \multirow{6}{*}{$\begin{array}{l}\text { Shipping } \\
\text { market } \\
\text { demand } \\
\text { conditions }\end{array}$} & Foreign trade dependence \\
\hline & & Cargo throughput \\
\hline & & Cargo throughput growth rate \\
\hline & & Container throughput \\
\hline & & Container throughput growth rate \\
\hline & & $\begin{array}{l}\text { The added value of the financial industry } \\
\text { accounts for the proportion of local GDP }\end{array}$ \\
\hline & \multirow{6}{*}{$\begin{array}{c}\text { Shipping } \\
\text { related } \\
\text { and supporting } \\
\text { industry factors }\end{array}$} & Year-on-year growth rate of financial \\
\hline & & industry's added value \\
\hline & & Premium income \\
\hline & & Insurance density \\
\hline & & Internet broadband user penetration rate \\
\hline & & Legal overall environment ( 1 - 4) \\
\hline & \multirow{2}{*}{$\begin{array}{l}\text { Auxiliary } \\
\text { factors }\end{array}$} & Special tariff easing $(1-4)$ \\
\hline & & Overall tax environment $(1-4)$ \\
\hline
\end{tabular}


proximity of each scheme to the positive ideal solution and the negative ideal solution. And sort by this. This method uses objective weighting to overcome the influence of the subjective factors of the researcher on the comprehensive evaluation, which makes the evaluation results more reliable and credible [13].

a) First, build an evaluation matrix based on raw data.

$$
X=\left(x_{i j}\right)_{m \times n}
$$

Since the dimensions of the indicators are different, the dimensionless processing is first performed.

$$
\begin{gathered}
X^{\prime}=\left(x_{i j}^{\prime}\right)_{m \times n} \\
x_{i j}^{\prime}=\frac{x_{i j}-\min x_{i j}}{\max x_{i j}-\min x_{i j}}
\end{gathered}
$$

b) Normalize the matrix to obtain a matrix

$$
\begin{gathered}
P=\left(p_{i j}\right)_{m \times n} \\
p_{i j}=\frac{x_{i j}}{\sum_{i=1}^{m} x_{i j}}, j=1,2, \cdots, n
\end{gathered}
$$

c) Calculate the weights. Calculate the entropy value first:

$$
e_{j}=-k \sum_{i=1}^{m} p_{i j} \ln \left(p_{i j}\right), k>0, k=1 / \ln (m), e_{j} \geq 0
$$

Then calculate the difference coefficient:

$$
g_{j}=1-e_{j}
$$

Final determination of weights:

$$
w=\frac{g_{j}}{\sum_{j=1}^{n} g_{j}},(1 \leq j \leq n)
$$

d) Construct a weighted norm matrix based on weights:

$$
R=\left(r_{i j}\right)_{m \times n}=\left[\begin{array}{cccc}
w_{1} p_{11} & w_{2} p_{12} & \cdots & w_{n} p_{1 n} \\
w_{1} p_{21} & w_{2} p_{22} & \cdots & w_{n} p_{2 n} \\
\vdots & \vdots & & \vdots \\
w_{1} p_{m 1} & w_{2} p_{m 2} & \cdots & w_{n} p_{m n}
\end{array}\right]
$$

e) Calculate the Euclidean distance. The Euclidean distances from the comparison object to the positive ideal solution and the negative ideal solution are:

$$
D_{i}^{+}=\sqrt{\sum_{j=1}^{n}\left(r_{i j}-r_{j}^{+}\right)^{2}}, \quad D_{i}^{-}=\sqrt{\sum_{j=1}^{n}\left(r_{i j}-r_{j}^{-}\right)^{2}}
$$

among them:

$$
r_{j}^{+}=\left\{\max _{j} r_{j} \mid j=1,2, \cdots, n\right\}, \quad r_{j}^{-}=\left\{\min _{j} r_{j} \mid j=1,2, \cdots, n\right\}
$$

f) Calculate the relative proximity of the evaluation object to the ideal solu- 
tion:

$$
D_{i}=\frac{d_{i}^{-}}{d_{i}^{+}+d_{i}^{-}}, i=1,2, \cdots, m
$$

The larger the value of $\mathrm{Di}$, the better the evaluation object.

\section{2) Data sources}

The data in this article is taken from the Shanghai Statistical Yearbook, Shenzhen Statistical Yearbook, Hong Kong Statistical Yearbook, Hong Kong Shipping Statistics, Yearbook of Statistics Singapore, China Port Yearbook and the Hong Kong Census and Statistics Department (www.info.gov.hk), Singapore Statistics Bureau (singstat.gov.sg), Singapore Harbour Authority (www.mpa.gov.sg), etc. Among them, Hong Kong's per capita income data is taken from 2016 data, because the data is counted every five years, and the most recent one is 2016, then revised it to the price level of 2015.

\section{Empirical Analysis and Promotion Strategies}

\section{1) Empirical analysis}

Using the entropy weight Topsis method to analyze the competitiveness of the four shipping centers, the following results were obtained:

It can be seen from Table 2 that the rankings of the competitiveness of international shipping centers in 2005 and 2015 have not changed. Hong Kong ranks first, Singapore is second, and Shanghai and Shenzhen are third and fourth respectively. The gap in the competitiveness of shipping centers has changed. On the one hand, the overall gap has narrowed, but the overall gap between Shanghai, Shenzhen and Hong Kong and Singapore is still large. On the other hand, there is little difference between Shanghai and Shenzhen, and the gap between Shanghai and Shenzhen has widened. And the gap between Hong Kong and Singapore has shrunk rapidly, and the relative gap between Hong Kong and Singapore has remained basically unchanged. This empirical result is slightly inconsistent with the Xinhua-Baltic International Shipping Center Development Index report, but according to IBM's 2014 promotion of Hong Kong as an international shipping center status consultancy study, people who have used shipping services in Hong Kong and Singapore have evaluated the two. The difference is not great, but those who have not used Hong Kong shipping related services have a higher evaluation of Singapore. It can be seen that the real

Table 2. International shipping center competitiveness evaluation results.

\begin{tabular}{ccccc}
\hline Year & \multicolumn{2}{c}{2005} & \multicolumn{2}{c}{2015} \\
\hline City & Relative proximity & Ranking & Relative proximity & Ranking \\
\hline Hong Kong & 0.89665499 & 1 & 0.864039 & 1 \\
Singapore & 0.71953515 & 2 & 0.686221 & 2 \\
Shanghai & 0.09794338 & 3 & 0.300914 & 3 \\
Shenzhen & 0.04557051 & 4 & 0.000000 & 4 \\
\hline
\end{tabular}


strength of Hong Kong and Singapore is not much different, but Singapore's promotion and promotion in the shipping industry market It is better than Hong Kong, so it is reasonable to conclude that the empirical results.

According to the results of the evaluation of the competitiveness standard of the International Shipping Center of Table 3, the rankings and gaps of the guidelines of various shipping centers have changed. In terms of the conditions of production factors at the port, the rankings of the international shipping centers at the two points remained unchanged at the two points, and the overall gap narrowed. Hong Kong has always ranked first, but its dominant position has declined. There is almost no difference between Singapore and Singapore in 2015. The result is only 0.0013 , and the gap between Hong Kong and Shanghai is also reduced to 0.097, but Shenzhen is still at the bottom and the gap with Shanghai is widening. The reason for these changes is mainly due to the rapid economic development of Shenzhen and Shanghai in recent years. Although the gap in per capita indicators is still large, the overall gap with Hong Kong and Singapore has rapidly narrowed, and Singapore's overall economic development has begun to be slightly ahead of Hong Kong. Moreover, in terms of the infrastructure of the port and the improvement of the collection and distribution network system, several other shipping centers have achieved remarkable results, especially in Singapore, while Hong Kong has basically no change. This has both insufficient land supply and government support. Not enough factors. In addition, in terms of human resources, Hong Kong and Singapore are not dominant. This is closely related to Hong Kong's investment in education and the attractiveness of talents. In attracting foreign talent, Hong Kong's housing costs are relative to Singapore. Higher, air pollution levels are also higher, and for family-owned talents, children's schooling, family members are not as convenient as Singapore, Singapore's investment in attracting foreign talent is very large, such as providing access to

Table 3. International shipping center competitiveness criteria layer evaluation results.

\begin{tabular}{|c|c|c|c|c|c|c|c|c|c|}
\hline \multicolumn{2}{|l|}{ Year } & \multicolumn{4}{|c|}{2005} & \multicolumn{4}{|c|}{2015} \\
\hline Criteria layer & City & Hong Kong & Shanghai & Singapore & Shenzhen & Hong Kong & Shanghai & Singapore & Shenzhen \\
\hline \multirow{2}{*}{$\begin{array}{l}\text { Conditions of } \\
\text { shipping product } \\
\text { on factors }\end{array}$} & $\begin{array}{l}\text { Relative } \\
\text { proximity }\end{array}$ & 0.710292 & 0.314256 & 0.604651 & 0.300287 & 0.560509 & 0.463411 & 0.559213 & 0.267606 \\
\hline & Ranking & 1 & 3 & 2 & 4 & 1 & 3 & 2 & 4 \\
\hline \multirow{2}{*}{$\begin{array}{l}\text { Shipping market } \\
\text { demand conditions }\end{array}$} & $\begin{array}{l}\text { Relative } \\
\text { proximity }\end{array}$ & 0.518425 & 0.459024 & 0.573209 & 0.408646 & 0.485360 & 0.554828 & 0.608145 & 0.335565 \\
\hline & Ranking & 2 & 3 & 1 & 4 & 3 & 2 & 1 & 4 \\
\hline \multirow{2}{*}{$\begin{array}{l}\text { Shipping related } \\
\text { and supporting } \\
\text { industry factors }\end{array}$} & $\begin{array}{l}\text { Relative } \\
\text { proximity }\end{array}$ & 0.928932 & 0.105167 & 0.655324 & 0.188476 & 0.804394 & 0.300761 & 0.477584 & 0.142030 \\
\hline & Ranking & 1 & 4 & 2 & 3 & 1 & 3 & 2 & 4 \\
\hline \multirow[t]{2}{*}{ Auxiliary factors } & $\begin{array}{l}\text { Relative } \\
\text { proximity }\end{array}$ & 1 & 0 & 0.677631 & 0 & 1 & 0 & 0.677631 & 0 \\
\hline & Ranking & 1 & 3 & 2 & 3 & 1 & 3 & 2 & 3 \\
\hline
\end{tabular}


foreign talent The door relocation services, including the provision of housing allowances and international education allowances, make foreign talents have no worries. From the above analysis, it can be seen that Hong Kong's dominant position in terms of port production factors has declined, mainly due to the slowdown in Hong Kong's economic development, the ineffectiveness of port infrastructure improvement, and the lack of training and attraction of relevant talents.

In terms of demand conditions in the shipping market, Singapore has always been in a leading position, while Hong Kong has been overtaken by Shanghai, from second to third, and Shenzhen is still at the bottom. This conclusion is also consistent with the global container port ranking since 2005. Since 2005, Hong Kong's container throughput has been declining. Shanghai and Singapore have gradually expanded their port demand, especially Shanghai has been sitting in a global container port for several years. The first throne. This aspect is due to the fact that in recent years, Shanghai has built an international shipping center with the support of the government, and has invested a lot of manpower and material resources to make its hard center and soft environment of the shipping center constantly improving. On the other hand, due to the high cost, Hong Kong lost its advantage in the fierce competition with the surrounding ports. According to the Hong Kong Port Development Strategy 2030, the handling fee of Hong Kong port terminal is about $36 \%$ higher than that of other Pearl River Delta ports. The cost is also much higher than the Pearl River Delta port. At the same time, Hong Kong and Singapore, as established trade centers, have a leading position in foreign trade because of their superior geographical position and a free port policy. Hong Kong is slightly better than Singapore. This is Hong Kong's neighboring ports such as Shenzhen Port and Guangzhou Port. In the case of a rapid rise, one of the reasons for the fact that the market share continues to shrink but still has a place. From the above analysis of the performance of the shipping market demand conditions and its causes, Hong Kong should strengthen the attractiveness of its ports, and handle the relationship with the surrounding ports to clarify their respective positioning.

In terms of shipping-related and supporting industry factors, although the overall gap has narrowed during the decade, Hong Kong is still far ahead. The gap between 2015 and Singapore is still at 0.32681, while Shanghai is surpassing Shenzhen to rise to third, but still behind Singapore. The shipping related and supporting industries mainly include information, finance, and legal services. Hong Kong has a long history as a global financial center, trade center and information and communication center, and implements the common law legal system and free port policy. It is not surprising that this result is achieved. Although Singapore has been a financial center for a long time, it still has a gap with the overall financial industry development in Hong Kong. In terms of the development of the information industry, Singapore's government is more dominant than the "freedom of intervention" in Hong Kong. The management of etc. is more strict. Shanghai and Shenzhen are developing rapidly in these industries, but due to the late start, and Hong Kong and Singapore attach great im- 
portance to the development of these industries, they also have a first-mover advantage, so there is still a big gap. In fact, Hong Kong has also developed very well in shipping finance, shipping insurance and arbitration, thanks to the development advantages of shipping-related and supporting industries.

In terms of supporting factors, the two points ranked the same, Hong Kong first, Singapore second, Shanghai and Shenzhen third. The article mainly reflects the degree of special tariff easing and the overall tax environment of government behavior. At two points in the study, Hong Kong has a lower tax rate than Singapore, Singapore is lower than Shanghai and Shenzhen, and Hong Kong and Singapore have always implemented a free port policy. In Shanghai and Shenzhen, the free trade zone was established at the second time, and the open volume of the free trade zone is still relatively small compared to the free port. Of course, the establishment of the bonded zone and the free trade zone in the mainland will make it more competitive with Hong Kong. To be fierce, these have an impact on the construction of international shipping centers and their competitiveness.

\section{2) Promotion strategy}

From the above empirical analysis, the most direct and fierce competitor of the Hong Kong International Shipping Centre is still Singapore, but the two actually have their own strengths, and then according to the changes in the competitiveness of the target layer and the criteria layer of each shipping center. And the cause of combing, we can propose a targeted strategy from the perspective of competition and cooperation to enhance the competitiveness of Hong Kong's international shipping center.

a) From a competitive perspective, Hong Kong can conduct comprehensive and targeted development based on the differences between the empirical results and other international shipping centers. As Hong Kong leads in the shipping-related and supporting industries including the financial, information and legal service environment and the overall tax environment, it is in a weak position in terms of port infrastructure, collection and distribution network system and port demand on behalf of port production factors. And in terms of human resources environment, it is not superior to Singapore. Therefore, on the one hand, we must continue to strengthen and improve the collection and distribution network system and port infrastructure construction, strengthen port technology and information construction, try to reduce various costs, improve port production technology and efficiency, and respond to obstacles caused by insufficient land supply. To enhance the attractiveness of the port to enhance its competitiveness, and at the same time continue to maintain its status as an international arbitration center. On the other hand, while further developing the high value-added shipping service industry, it is important to develop aspects that differ from its direct competitor Singapore. As for ship financing, the empirical results show that Hong Kong's financial environment is better than Singapore at two points, and according to the Executive Director of the Hong Kong Shippers' Committee, He Liji stressed that Hong Kong's financial system is more 
robust than Singapore. In fact, Hong Kong has long been a free port and its economic freedom is very high. It is different from Singapore's strong government-controlled financial market. Hong Kong's financing costs are lower because Hong Kong has more diversified and largely open capital. The market, and Hong Kong's banking industry is very developed, and there are many banks that can provide ship financing. Another example is maritime information service. According to the empirical results, Hong Kong is better than Singapore in terms of information service environment. This is not unrelated to Hong Kong's 22-year history as the region with the highest degree of global economic freedom and its long history as an information and communication center. Whether it is port-based business or shipping brokerage, finance and insurance services, a strong media is needed to provide information and information services. No city has the same shipping industry media as London. As the shipping center shifts eastward, the Asia-Pacific region also needs a shipping center with one-stop service. Therefore, the development of the maritime information service industry, which is indispensable as a shipping service industry, is indispensable. Hong Kong can use its strengths to nurture and develop its printing, networking and social media, and strive to become a global maritime information service center. In addition, combined with the reality, Singapore is well-known for its industrial and high-tech industries. It is a well-known international ship repair and decoration center and an international ship fuel supply center. Singapore is more concerned with marine R \& D. Its key research areas include: the marine environment and Resources, ships, terminal and port operations and security, maritime IT and communications, maritime transport and logistics, offshore and offshore engineering [1]. While Hong Kong has advantages in terms of ship registration and ship financing, Hong Kong should continue to expand its advantages in ship registration. On the one hand, in the ranking of global ship registration, Hong Kong is located in front of Singapore, and is much higher than Shanghai and Shenzhen. Therefore, it should continue to expand its advantages. On the other hand, it is the rapid development of trade brought about by the "One Belt, One Road" initiative. The demand for class shipping services includes the increase in ship registration, Hong Kong as an important node of the "Belt and Road" and its unique relationship with China as the "Belt and Road" proponent and leader, and the procedures in Hong Kong are in Chinese and English. The overall tax environment is also superior, which makes Hong Kong more advantageous than Singapore. In addition, from the empirical results, it can be seen that Hong Kong's human resources environment is not as good as that of Singapore. Therefore, on the one hand, Hong Kong should improve the overall human resources environment, and increase investment in shipping education in a targeted manner, and strengthen the training of professional maritime talents and navigation. Relevant legal, financial and insurance talents, strengthen cooperation with personnel training in other regions, and also strengthen the employment appeal of the maritime industry to the public. On the other hand, it is necessary to increase the intensity of attracting foreign tal- 
ents and improve the living environment of Hong Kong such as housing costs, ecological environment, and convenience of living. Learn from Singapore's policies to attract talent, such as housing allowances and international education allowances.

b) From the perspective of cooperation, it can be seen from the empirical results that Shanghai and Shenzhen still have a large gap with the Hong Kong International Shipping Center, and they are not as close to Hong Kong as the related and supporting industries closely related to the high value-added shipping service industry. Competition, but the space for cooperation is still large. In addition, due to the unique relationship with the mainland, coupled with the "One Belt and One Road" initiative in recent years and the planning of the Greater Bay Area of Guangdong, Hong Kong and Macao, Hong Kong's cooperation with Shenzhen and Shanghai in this context can give full play to the institutional diversity brought about by "One Country, Two Systems" and The unique advantage of complementarity. Therefore, on the one hand, we must seize the opportunity of deep integration with the mainland brought by the planning of Guangdong, Hong Kong and Macao Dawan District, and handle the relationship with the surrounding shipping centers such as Shenzhen. As Shenzhen has more advantages in shipping than containers in Hong Kong, but in shipping The high-end shipping services industry, such as finance and international arbitration, is far from Hong Kong. Therefore, Hong Kong should establish a port group with reasonable cooperation and cooperation with Shenzhen Shipping Center and surrounding ports. With the further opening up of the cooperation between Guangdong and Hong Kong, Hong Kong will be The advantages of high-end shipping services such as financial insurance in shipping centers are combined with the advantages of Shenzhen's physical shipping industry. The port combination mode is also the main development situation of the current international shipping center. There are mainly single hub shipping centers and dual hub shipping centers. In the choice of international shipping center mode, the dual hub mode is better than the single hub mode. This is because the dual hub The model is more conducive to improving the competitiveness of shipping centers and sharing risks. It is also an inevitable trend that the single hub mode shifts to the dual hub mode [14]. Therefore, although the Shenzhen International Shipping Center is still not as good as the Hong Kong International Shipping Center, if the two can establish a port group with reasonable division of labor and complementary functions, and gradually develop into a more mature port combination model of Shenzhen and Hong Kong, for upgrading Shenzhen and Hong Kong. The competitiveness of international shipping centers will be beneficial. On the other hand, in the face of the rapid rise of the Shanghai shipping center, the competition between Hong Kong and Shanghai shipping centers began to increase, but in the context of the "One Belt, One Road" initiative, the demand in the shipping market expanded rapidly, enough to support multiple shipping centers. Therefore, the Hong Kong and Shanghai shipping centers should be consistent with each other, minimize the intensity of domestic compe- 
tition, avoid vicious competition and redundant construction, give full play to the advantages of "one country", and strengthen the division of labor and cooperation to achieve a win-win situation. In fact, the hinterland and radiation range of the two shipping centres in Hong Kong and Shanghai are also different. The radiation range of the Shanghai shipping centre is mainly in the northeast, while Hong Kong is mainly in Southeast Asia. Therefore, the two can agree on the division of labor in this respect. At the same time, because Hong Kong is better than Shanghai in terms of financial services environment, Hong Kong has a more diversified and larger open international capital market, which makes financing more convenient, lower cost, and more convenient for capital operation. Closer to its hinterland customers, business operations are more appropriate in Shanghai, but due to the impact of foreign exchange control, taxation system and brokerage business, the funds are more suitable for Hong Kong, so the two can be based on their respective advantages. Cooperation, forming a division of labor in Shanghai for business operations and capital operation in Hong Kong. In addition, in terms of shipping talents, the two can also carry out more exchanges and interactions.

\section{Conclusion}

This paper sorts out the factors affecting the international shipping center and related concepts as well as the competitiveness of international shipping centers, and builds an international shipping center competitiveness index system based on Porter's “diamond model". Then using the entropy weight Topsis method to analyze the competitiveness of the four international shipping centers in Hong Kong, Singapore, Shanghai and Shenzhen at different points in time. These four international shipping centers are located in the Asia-Pacific region, competitive and competing with each other. More intense, according to the analysis of the empirical results, from 2005 to 2015, the rankings of the competitiveness of the four shipping centers have not changed, Hong Kong has been leading, followed by Singapore, Shanghai, Shenzhen, but the overall gap has narrowed, Hong Kong shipping. The relative advantages of the center have declined, and the competitiveness of the standards of the shipping centers has also changed. At the same time, the causes of the changes in the competitiveness of various shipping centers have been explored. Based on the analysis of empirical results, this paper sorts out the advantages and disadvantages of Hong Kong and the differences with other shipping centers. From the perspective of cooperation and competition, combined with the "One Belt, One Road" initiative and the opportunity brought by the planning of Guangdong, Hong Kong and Macao Dawan District, targeted. The strategy of promoting the competitiveness of Hong Kong's international shipping center was put forward. First, we must continue to strengthen and improve the port infrastructure construction and collection and distribution network system. Second, we must focus on the development of high value-added shipping services while focusing on the differences between its direct competitors, such as ship financing. Maritime information services and ship registration 
should also improve the overall human resources environment and increase the intensity of attracting foreign talents. Thirdly, it should establish a port group with reasonable division and cooperation with Shenzhen Shipping Center and surrounding ports, and combine the advantages of high-end shipping service industry such as financial insurance of Hong Kong shipping center with the advantages of the physical shipping industry in the Mainland, and operate in shipping business. In terms of capital operation, it can form a division of labor with Shanghai, and it can also cooperate with Shanghai in terms of human resources.

\section{Conflicts of Interest}

The author declares no conflicts of interest regarding the publication of this paper.

\section{References}

[1] Wang, L. and Ning, Y. (2010) The Trend of International High-End Shipping Service Industry and Ningbo's Strategy. Economic Geography, Changsha, 2.

[2] Wang, Y. (2014) The Development Status of Hong Kong's Shipping Industry and the Way out for the Construction of International Shipping Centers. World Shipping, Dalian, 10.

[3] Qu, J. (2007) The Significance of Hong Kong and Shenzhen Building an International Shipping Center. Open Herald, Shenzhen, 2.

[4] Zeng, J. (2013) Analysis of the Transformation and Upgrading of Hong Kong International Shipping Center and Its Influencing Factors. Master's Thesis of Jinan University, Guangzhou.

[5] Xu, X. (2003) Analysis of Competitive Advantages of Shanghai International Shipping Center. PhD Thesis of Hohai University, Nanjing.

[6] Wu, X. (2004) The Soft Environment Construction of Shanghai International Shipping Center and the Role of Government. Master's Thesis of Shanghai Maritime University, Shanghai.

[7] Yang, J. (2005) Theory and Practice of Modern Port Development. PhD Thesis of Shanghai Maritime University, Shanghai.

[8] Ma, S. (2011) What Kind of International Shipping Center Should Shanghai Be. Pearl River Water Transport, Guangzhou, Z1.

[9] Li, J. (2003) The Construction of Shanghai International Shipping Center Has Joys and Worries. China Port, Shanghai, 5.

[10] Ma, S. (2007) Soft Power Is the Key to Building Shanghai International Shipping Center. Water Transportation Management, Shanghai, 5.

[11] Zhang, L. (2008) The Experience and Enlightenment of London's Development of International Shipping Center. Port Economy, Tianjin, 9.

[12] Wang, X. (2006) Discussion on the Factors of Competitiveness of International Shipping Centers. Port Economy, Tianjin, 2.

[13] Li, W. and Yang, G. (2014) Comprehensive Comparison and Time Evolution Analysis of Urban Competitiveness Based on TOPSIS Method of Entropy Right-Taking "Central Four Corners" Urban Agglomeration as an Example. Philosophy and Social Sciences, Guangzhou, 10. 
[14] Gao, W. (2012) Development Trends and Empirical Research of International Shipping Centers-Taking the Construction of Tianjin Northern International Shipping Center as an Example. Exploration of Modern Economy, Nanjing, 7. 